\title{
Intelligence, Beliefs on IQ and Learning Style predict Academic Performance in Mechanical Engineering Students
}

\author{
Amir Jahanian Najafabadi ${ }^{1}$, Hadis Imani ${ }^{2}$, Reza Beygi ${ }^{3}$, \\ António Mendes Lopes ${ }^{4}$, Lucas Filipe Martins da Silva ${ }^{5}$ \\ ${ }^{1}$ Department of Psychology \& Methods, Jacobs University Bremen gGmbH, Research IV, \\ Campus Ring 1, 28759 Bremen, Germany (Corresponding author) \\ (a.jahaniannajafabadi@jacobs-university.de) ORCID 0000-0002-9246-5141; ${ }^{2}$ Department of \\ Psychology \& Methods, Jacobs University Bremen gGmbH, Research IV, Campus Ring 1, 28759 \\ Bremen, Germany (h.imani@jacobs-university.de) ORCID 0000-0002-6090-156X; ${ }^{3}$ INEGI - \\ Institute of Science and Innovation in Mechanical and Industrial Engineering, Faculty of \\ Engineering campus, Rua Dr. Roberto Frias, 4200-465 Porto, Portugal (rbeygi@inegi.up.pt) \\ ORCID 0000-0002-0110-1642; ${ }^{4}$ Department of Mechanical Engineering, Faculty of \\ Engineering, University of Porto, Rua Dr. Roberto Frias, 4200-465 Porto, Portugal \\ (aml@fe.up.pt) ORCID 0000-0001-7359-4370; 5Department of Mechanical Engineering, \\ Faculty of Engineering, University of Porto, Rua Dr. Roberto Frias, 4200-465 Porto, Portugal \\ (lucas@fe.up.pt) ORCID 0000-0003-3272-4591
}

\begin{abstract}
In this study we aimed to investigate whether beliefs on intelligence, intelligence quotient, and learning styles predict academic performance among students in mechanical engineering. For this purpose, forty-two students from the Department of Mechanical Engineering of the University of Porto were recruited among the available population. Participants responded to the measurement of this study via a Google form and on a voluntary basis. To investigate our hypothesis, beliefs on intelligence inventory, learning style questionnaire, Raven's Progressive Matrices IQ test and their GPA as an indicator of their academic performance were used. Correlation analysis revealed significant effects between reflector learning style and academic achievement. Multiple regression also revealed a significant main effect of the reflector learning style on academic performance $(p=.044)$. This study further revealed no significant correlation between other learning styles, beliefs on intelligence, intelligence quotient and academic performance.
\end{abstract}

Author Keywords. Intelligence, Beliefs on IQ, Learning Style, Academic Success, Engineering Student.

Type: Research Article

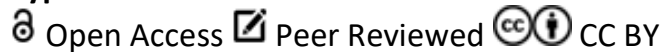

\section{Introduction}

Both predictive factors and improvement in academic performance have been concerns of educational psychologists for a few decades (Busato et al. 2000). Despite the various studies that emphasized on the important predictors for academic achievement, a study reported that $50 \%$ of the students who were expected to fail in the higher education ended up with success, compared with $30 \%$ of the students who ended up failing while they were expected to be successful in their academic achievement (Mouw and Khanna 1993). In fact, there are several factors involved in predicting academic performance. In addition to the intelligence quotient (IQ); learning style, executive function e.g., time planning, goal setting and personality factors are crucial for academic performance, especially at higher educational levels, such as universities (Chamorro-Premuzic and Furnham 2003; Čavojová and Mikušková 2015). As 
reported by Kappe and van der Flier (2012), combination of IQ, personality and motivation predicts $33 \%$ of the variance of grade point average (GPA) and $30 \%$ of variance of time that is needed to graduate. Moreover, academic performance is a broad concept which is related to the requirements of school, personal performance, individual personality and the development of students itself (Čavojová and Mikušková 2015). According to the Oxford English dictionary, IQ is defined as a person's degree or measure of understanding. The role of IQ in school performance has been questioned in various studies, with a greater focus on personality factors (Mehta and Kumar 1985). In addition, to measure academic performance, grades and GPA are the most widely used and reliable guides (York, Gibson, and Rankin 2015). It is believed that most students are capable of learning regardless of their IQ. Due to this fact, the educator should get rid of this mindset that the IQ is not malleable and is fixed (Aragón, Eddy, and Graham 2018). The definition and measurement of IQ is the subject of this research. The importance of the IQ test for academic performance has decreased in recent years. However, this parameter is still considered as an important factor in predicting academic success, but alongside other factors. The Raven's Progressive Matrices IQ test (IQ score) is one of the well-established methods to measure cognitive intelligence (Raven and Court 1998) which is defined as a person's ability to adapt to the environment (Mclntosh, Dixon, and Pierson 2018). In a study performed on rural high school students, He et al. (2021) reported that lower cognitive ability, as measured by the Raven IQ test, was strongly related to lower academic performance. They also found that personality traits, such as hard work and perseverance cannot compensate for poor cognitive ability to achieve academic performance. In another study performed by Bottenhorn et al. (2021), it was found that IQ is not related to academic results, but in the case of physics courses, student's performance was significantly related to IQ. Another study in school age children also found that IQ is significantly related to academic performance (Akubuilo et al. 2020).

In addition to cognitive ability, individual differences in motivation, interest and self-concept can also influence academic performance (Raven and Court 1998). Expectancy value theory can best conceptualize achievement motivation (Meyer, Fleckenstein, and Köller 2019). According to expectancy value theory, achievement motivation depends on two elements: (a) expectancy of success as students' beliefs of how well they will do on the activity, and (b) value beliefs describing the extent to which students' value the activity (Meyer, Fleckenstein, and Köller 2019). Both factors are essential to have a high academic achievement. Adaptability and positive behavioral engagement were not directly associated with GPA, whereas negative behavioral engagement is (Collie, Holliman, and Martin 2017). In another study (Jackson and Rushton 2006) performed on both genders at the age of 17-18 year, the authors found that the IQ of males was slightly higher than females by 3.63 IQ points. This result was independent of race and socioeconomic level. A recent study in school age children reported by Akubuilo et al. (2020), revealed that several factors positively impact the IQ level and consequently predict academic performance e.g., being from upper social class, studying in private school, family size.

The mindset about IQ also influences academic achievement. Two beliefs, namely growth mindset and fixed mindset, relate to the belief that a person's IQ is changing or fixed, respectively (Li and Bates 2020). People with a solid mindset avoid any attempt to complete the difficult tasks, as any challenge appears to them as a sign of lack of IQ. These people are committed to the tasks that are less likely to fail (Li and Bates 2020). The students with a growth mindset show greater motivation and perseverance and achieve greater academic success (Mangels et al. 2006). Those who believe that IQ is a fixed entity (entity theorists) tend 
to emphasize "performance goals", which makes them vulnerable to negative feedback and likely to disconnect from challenging learning opportunities. In contrast, students who believe $\mathrm{IQ}$ is malleable (incremental theorists) tend to emphasize" learning goals" and rebound better from occasional failures (Mangels et al. 2006). The belief that IQ is malleable has important consequences for performance and motivation. The belief that IQ is "fixed" was indicative of lower performance goals (De Castella and Byrne 2015). The results of some studies such as Li and Bates (2020), however, suggest that other factors besides the growth mindset can also contribute to academic level, as they concluded that the growth mindset has no influence on academic success.

Overall, results of a study by Furnham, Chamorro-Premuzic, and McDougall (2003) suggest that once a suitable level of IQ is reached, personality variables play an increasing role in educational outcomes. In a study performed by Duarte, Lopes, and da Silva (2021) the performance of the mechanical engineering students at the University of Porto was correlated with their performance at the end of high school, but found no significant correlation between these two factors.

Moreover, learning style and its components are defined as a key factor that influences the learning process of the students and their academic performance (Abouzeid et al. 2021), and these factors are based on the individual differences (Biabani and Izadpanah 2019). Various models e.g., Virtual Aural Read/Write Kinesthetic (VARK) model (Abouzeid et al. 2021), Dunn \& Dunn Model (Schick 1979), and Grasha model (McLaughlin 1996) are used to categorize the learning styles which relate to the way one learns and differs from individual to individual (Phoong, Phoong, and Phoong 2021). Kolb and Kolb (2006) defined four fundamental learning styles e.g., activist, reflector, theorist and pragmatist. As for activists, he believes that students with this learning style want more practice tasks rather than theory, and they have better learning when there are a lot of actions and excitement, or when they can respond to a challenge and take risks. The students with activist learning style are looking to be in the limelight and to focus on new experiences that they can do, and activities such as games and problem solving. Students with the reflector learning style look for sufficient time to let them read and discuss, and when there are some opportunities that they observe and consider and make sure have enough time to think before any action or contribution. These students from this point of view are asked to make reports of the analyses carefully and finalize a view without being put under pressure. Students with pragmatist style are looking for shortcuts and tips compared with other categories and willing to dive into the problems that can be probed in some depth. In addition, students with the last learning style, as theorists, are intended to form a part of a conceptualization and explore the interrelationships amongst elements. These students have a clear and obvious purpose to the activities and analyze the situations before they generalize the findings (Sugarman 1987; Kolb and Kolb 2006).

Knowing the learning style of the students helps teachers to enable them to retain the information much longer and, consequently, apply this information more efficiently and effectively, and have more positive post-course attitudes toward the subject as well as in their personal life (Felder 1993). Kolb (2005) reported that these four fundamental learning styles lead to concrete experience and active experimentation, therefore adapting academic materials is necessary and will facilitate the learning process of individuals. This effort will increase the benefit of learning particularly for students with low and moderate academic achievement (Zin, Zaman, and Noah 2002).

The majority of studies on learning styles are limited to the identification of learning styles and only are descriptive (Boström 2011; Joy and Kolb 2009; D'Amore, James, and Mitchel 
2012; Suliman 2006), however, still little is known on how learning style impacts academic performance of mechanical engineering students together with beliefs on IQ, IQ and whether beliefs on IQ plays a significant role in this context.

The aim of the present study is to examine whether the academic performance of students in mechanical engineering can be predicted by their $I Q$, beliefs on $I Q$ and their different learning style. Findings will help educational psychologists and teachers to design and promote effective and efficient learning and academic achievement, and to develop insights into the more favorable learning style in the educational system and student's satisfaction. The findings also contribute to better understanding of learning style in mechanical engineering students and the impact of their learning style, their IQ and their beliefs about IQ on their academic performance. This helps to improve and optimize the teaching style of the lecturers at the universities. The outcome of this study will also motivate lecturers to make use of appropriate methods of teaching and pay attention to individual differences. Therefore, two research questions were raised to understand, first, whether there is a significant correlation between IQ, beliefs on IQ and their learning styles, and second, whether these elements predict academic performance which is measured with GPA grade of the students in mechanical engineering.

\section{Methods}

\subsection{Participants}

For this study participants were recruited from the Department of Mechanical Engineering of University of Porto. Because of the global Covid-19 restrictions and lockdown, this study was adapted and conducted during Spring 2021 via online platforms. We announced this research to the student body with the population of 200 students enrolled in the engineering program and forty-two participants voluntarily filled out and completed the measurements of this study via provided Google Form. Students were briefly informed about the purpose of this study and agreed on a data privacy agreement. This study was conducted in compliance with the rules of the Declaration of Helsinki (World Medical Association 2013), and participants signed the consent form. The age range of the participants was $18-29$ years and the mean age of participants was 21.2 (SD $=2.6$ ).

\subsection{Measurements}

For this study three different measurements were used to examine whether IQ, beliefs on IQ and learning style predict academic performance in mechanical engineering students. The items for each measurement were transferred to the Google form and then data curation and formal analysis were performed using statistical software. The time to respond to the measurement of this study was 60 minutes which included the response to the IQ test maximum 20 minutes.

\subsection{Beliefs on intelligence}

To assess beliefs on IQ, the meaning and measurement of IQ questionnaire was used (Swami et al. 2008; Furnham, Chamorro-Premuzic, and McDougall 2003). This questionnaire consists of a 30-items designed by a group of experts in IQ and its aspects. All the 30 statements are related to what $I Q$ is, as well as social implications of $I Q$, and the source and stability between group differences in IQ. The internal consistency of this measurement is reported based on Cronbach's alpha $=0.81$. The internal consistency in our research was also indicated as Cronbach's alpha $=0.77$. 


\subsection{Learning style questionnaire}

This questionnaire is designed by Kolb (1984) and revised by Kolb (2006, version 3.1) to find out preferred learning styles among adults. This questionnaire helps people to be aware of their learning preferences and the learning habits that they developed over the years. The revised version of this questionnaire consists of 80 items (takes approximately 10 minutes to complete), which participants are required to mark whether they agree or disagree in the blank box. This questionnaire investigates four different fundamental learning styles including activist, reflector, theorist and pragmatist. The scoring for this questionnaire is to count each item that is ticked and consider no point for items that are crossed, and the total score for each learning style to determine the strength of their preference is calculated. Cronbach's alpha was calculated for each of the four-learning style, with all scales demonstrating acceptable to excellent internal consistency in the first measurement (activist: $\alpha=0.66$, reflector: $\alpha=0.89$, theorist: $\alpha=0.87$, pragmatist: $\alpha=0.88$ ).

Table 1 , indicates each learning style with corresponding items. The strength of the learning style is categorized as very strong preference, strong preference, moderate preference, low preference and very low preference (cf., Table 2). Table 3 reports the mean and SD for learning style questionnaire and all types.

\begin{tabular}{|c|c|c|c|c|}
\hline & \multicolumn{4}{|c|}{ Questions Number } \\
\hline & 2 & 7 & 1 & 5 \\
\hline & 4 & 13 & 3 & 9 \\
\hline & 6 & 15 & 8 & 11 \\
\hline & 10 & 16 & 12 & 19 \\
\hline & 17 & 25 & 14 & 21 \\
\hline & 23 & 28 & 18 & 27 \\
\hline & 24 & 29 & 20 & 35 \\
\hline & 32 & 31 & 22 & 37 \\
\hline & 34 & 33 & 26 & 44 \\
\hline & 38 & 36 & 30 & 49 \\
\hline & 40 & 39 & 42 & 50 \\
\hline & 43 & 41 & 47 & 53 \\
\hline & 45 & 46 & 51 & 54 \\
\hline & 48 & 52 & 57 & 56 \\
\hline & 58 & 55 & 61 & 59 \\
\hline & 64 & 60 & 63 & 65 \\
\hline & 71 & 62 & 68 & 69 \\
\hline & 72 & 66 & 75 & 70 \\
\hline & 74 & 67 & 77 & 73 \\
\hline & 79 & 76 & 78 & 80 \\
\hline & - & - & - & - \\
\hline Totals: & Activist & Reflector & Theorist & Pragmatist \\
\hline
\end{tabular}

Table 1: Four learning style and corresponding items 


\begin{tabular}{|c|c|c|c|c|}
\hline Activist & Reflector & Theorist & Pragmatist & \\
\hline $\begin{array}{l}20 \\
19 \\
18 \\
17 \\
16 \\
15 \\
14 \\
13\end{array}$ & $\begin{array}{l}20 \\
19 \\
18\end{array}$ & $\begin{array}{l}20 \\
19 \\
18 \\
17 \\
16\end{array}$ & $\begin{array}{l}20 \\
19 \\
18 \\
17\end{array}$ & $\begin{array}{l}\text { Very strong } \\
\text { preference }\end{array}$ \\
\hline $\begin{array}{l}12 \\
11\end{array}$ & $\begin{array}{l}17 \\
16 \\
15\end{array}$ & $\begin{array}{l}15 \\
14\end{array}$ & $\begin{array}{l}16 \\
15\end{array}$ & Strong preference \\
\hline $\begin{array}{c}10 \\
9 \\
8 \\
7 \\
\end{array}$ & $\begin{array}{l}14 \\
13 \\
12\end{array}$ & $\begin{array}{l}13 \\
12 \\
11\end{array}$ & $\begin{array}{l}14 \\
13 \\
12\end{array}$ & $\begin{array}{l}\text { Moderate } \\
\text { preference }\end{array}$ \\
\hline $\begin{array}{l}6 \\
5 \\
4 \\
\end{array}$ & $\begin{array}{c}11 \\
10 \\
9 \\
\end{array}$ & $\begin{array}{c}10 \\
9 \\
8 \\
\end{array}$ & $\begin{array}{c}11 \\
10 \\
9\end{array}$ & Low preference \\
\hline $\begin{array}{l}3 \\
2 \\
1 \\
0\end{array}$ & $\begin{array}{l}8 \\
7 \\
6 \\
5 \\
4 \\
3 \\
2 \\
1 \\
0\end{array}$ & $\begin{array}{l}7 \\
6 \\
5 \\
4 \\
6 \\
2 \\
1 \\
0\end{array}$ & $\begin{array}{l}8 \\
7 \\
6 \\
5 \\
4 \\
3 \\
2 \\
1 \\
0\end{array}$ & $\begin{array}{c}\text { Very low } \\
\text { preference }\end{array}$ \\
\hline
\end{tabular}

Table 2: The strength of the learning style

\begin{tabular}{|c|c|c|c|c|c|}
\hline & N & Minimum & Maximum & Mean & SD \\
\hline Activist & 42 & 2 & 15 & 9.5 & 3.3 \\
\hline Reflector & 42 & 10 & 19 & 14.9 & 2.1 \\
\hline Theorist & 42 & 8 & 17 & 13.1 & 2.5 \\
\hline Pragmatist & 42 & 5 & 19 & 12.38 & 3.1 \\
\hline Total Score & 42 & 39 & 59 & 49.9 & 5.1 \\
\hline
\end{tabular}

Table 3: Mean and SD for four types of learning styles

\subsection{Raven's Progressive Matrices IQ test (Raven, 1396)}

The Raven's Progressive Matrices IQ test, as an established and well-known international IQ test, is designed for both children and adults. In this study, we used the adult's version $(+15)$ consisting of 60 multiple choice questions that are listed in order of increasing difficulty. This test examines general human IQ and abstract reasoning as a non-verbal estimate of fluid IQ. In this test participants are asked to identify the missing element that completes each presented pattern in each item. In our study, questions were transferred into the online form and participants were asked to complete each missing element by choosing it from the given items. Then total IQ scores were computed based on the international instruction and standardized norm.

\subsection{GPA grade}

For this study, the last GPA grade of the students was used as an indicator of academic performance, and employed as a variable to investigate academic performance. Participants were asked to indicate their grade and the score received based on a self-report. The 
descriptive results were computed. Minimum and maximum grade were reported as 10 and 16.40 respectively, and the mean $12.9(S D=1.4$ ) calculated (see Figure 1 ).

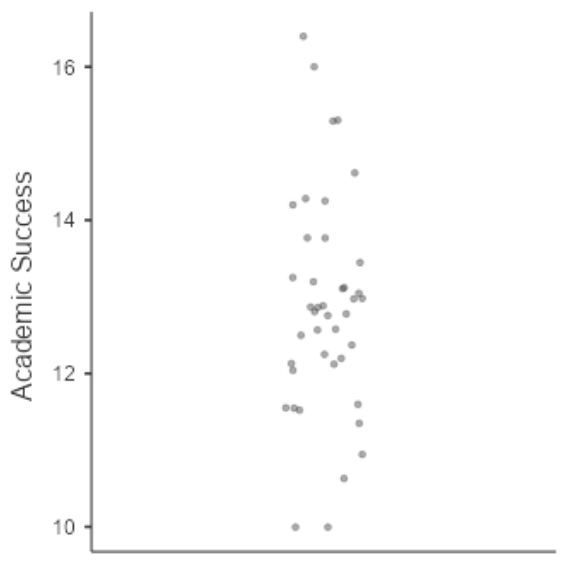

Figure 1: The distribution of grades as an indicator of academic performance

\section{Statistical Analysis}

Demographic information of participants is reported by using descriptive analysis. For inferential statistics, the scores from validated measurements of beliefs about IQ, Raven's Progressive Matrices IQ test and learning style were used to measure our hypothesis. Correlation analysis was used to determine the association between beliefs on IQ, IQ and learning style with academic performance. In addition, a regression model was applied to investigate whether beliefs on IQ, IQ and learning style predict academic performance among students in mechanical engineering. Inferential statistics were performed with the Jamovi software version 2.2.5 (The Jamovi Project 2021).

\section{Results}

Several classifications were made for different data combinations, and the most meaningful results are presented below.

Figure 2 shows beliefs on IQ versus IQ score. The data are classified into two groups, that is, students with low GPA (red squares, lower than 13.2), and the students with higher GPA (blue squares, higher than 13.2).

No significant correlation was revealed between IQ score and their beliefs on IQ, though the students with higher IQ scores are more likely to believe less on IQ. Only 26\% of those who have IQ scores higher than 130 got higher grades (inside the ellipse). This means that just having a high IQ does not guarantee a high academic performance.

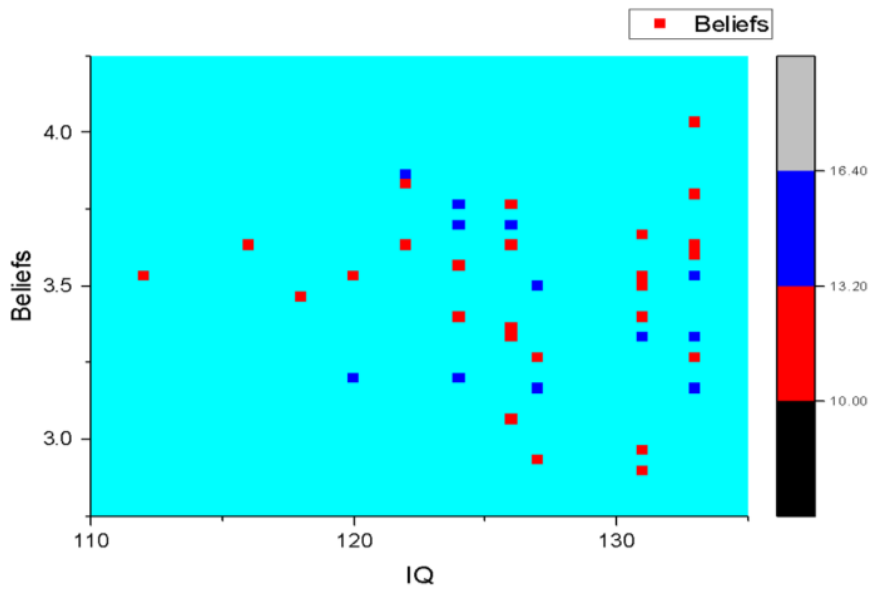

Figure 2: Beliefs on IQ versus IQ Scores 
Figure 3 shows the GPA of the students versus IQ Scores. The interesting point is that the students with higher GPA are those who have got higher IQ scores. This implies that a high IQ is therefore a prerequisite for higher academic success, but not everything.

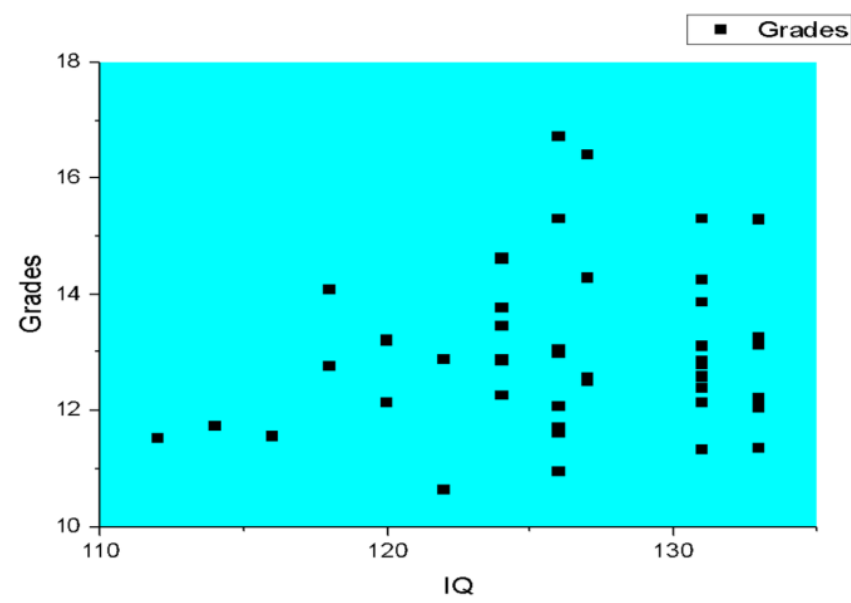

Figure 3: The GPA of the students versus IQ scores

Figure 4 shows the grades versus the pragmatist score, classified into two groups. Blue squares show the students with a high reflector score and the red squares show those with a low reflector score. A weak correlation can be seen between the pragmatist score and GPA. The students with a higher score on pragmatism tend to get lower GPA. More than $80 \%$ of students with a high GPA have a high score on reflector (marked in the upper square). On the other hand, the students with low reflector index have got low GPA (marked in lower square). It is noteworthy that having a high reflector index will not guarantee a high GPA, implying that there should be other variables that need to be considered.

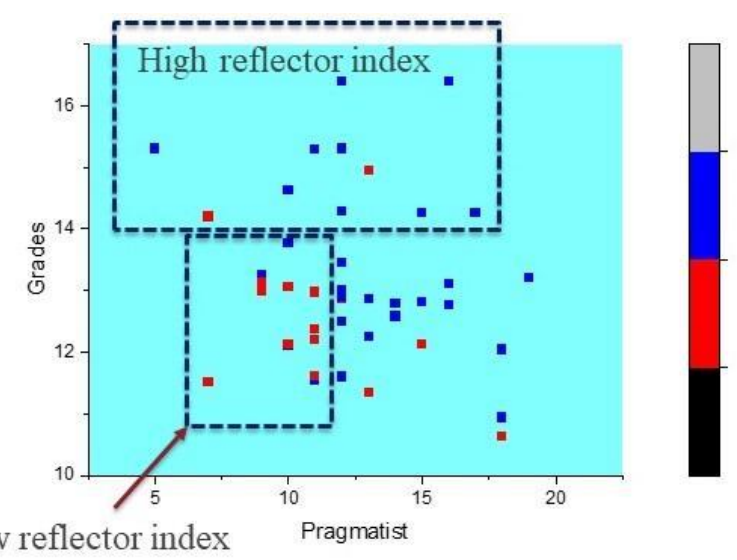

Figure 4: The grades of the students versus the pragmatist score, classified into two groups according to their reflector score

Results from Pearson correlation analyses indicated a significant and positive association between academic performance and reflector as a learning style $(r=0.309, p=0.47)$. But no significant association was observed between other types of learning style, IQ and beliefs on IQ with academic performance (cf., Table 4, for details see Figure 5). In addition, there was a significant and negative association between beliefs of IQ and reflector as a learning style ( $r=$ $-0.313, p=0.045)$. 


\begin{tabular}{clcccccc}
\hline & & IQ belief & IQ & Activist & Reflector & Theorist & Pragmatist \\
\hline Academic & Pearson & -0.257 & 0.152 & 0.086 & $.309^{*}$ & -0.039 & -.233 \\
performance & p-value & .1 & .336 & .588 & .047 & 0.805 & 0.138 \\
\hline Reflector & Pearson & $-0.313^{*}$ & 0.034 & $-0.369 *$ & -- & $0.307^{*}$ & 0.040 \\
& p-value & 0.045 & 0.829 & 0.016 & -- & 0.048 & 0.802 \\
\hline
\end{tabular}

Note. ${ }^{*} p<.05, * * p<.01, * * * p<.001$

Table 4: Correlation of beliefs on IQ, IQ scores and learning style with academic performance

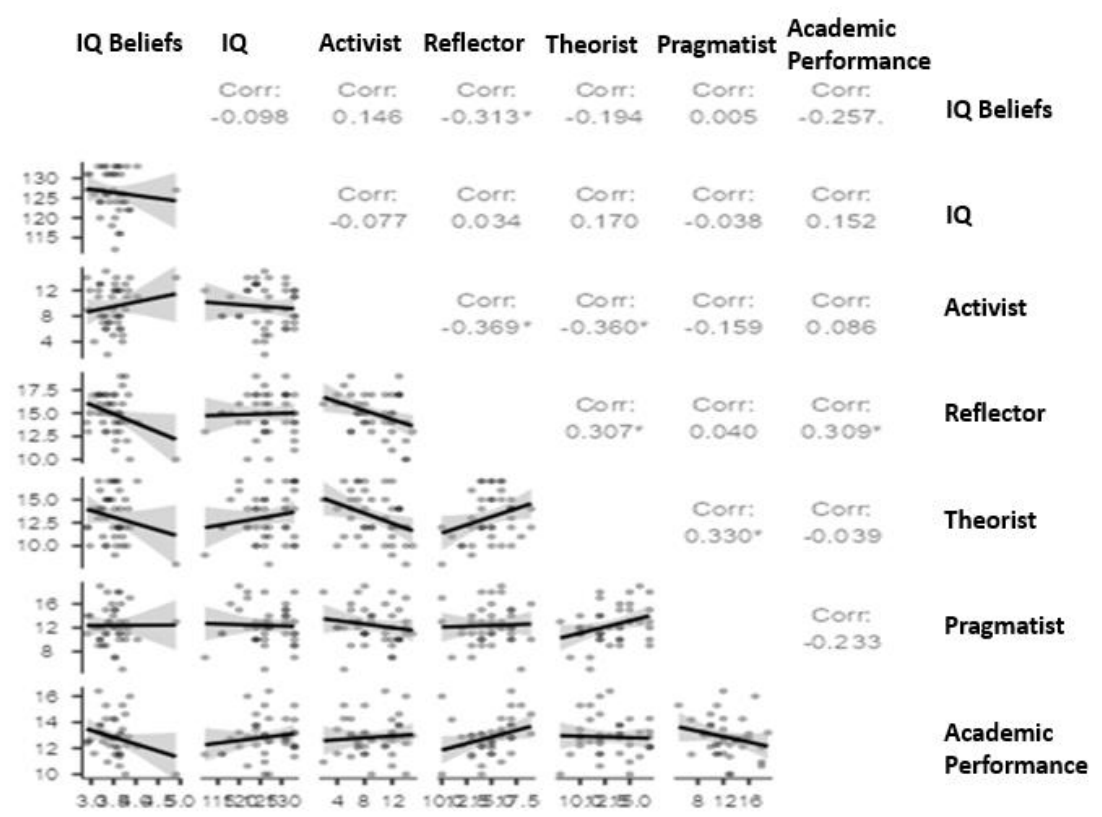

Figure 5: Correlation matrix between beliefs on IQ, IQ scores, learning styles, and academic performance

Multiple regression was used to study academic performance as a dependent variable, and beliefs on IQ, IQ scores and four types of learning style as factors. This model was fitted to investigate whether academic performance can be predicted by beliefs on IQ, IQ scores and each of the four types of learning style.

Multiple regression was performed to investigate academic performance (final grade) as a dependent variable. $I Q$, beliefs on $I Q$, reflector, pragmatist, activist and theorist were used as predictors. The findings revealed reflector learning style as a predictor of academic performance in students of mechanical engineering ( $\mathrm{B}=0.230, \mathrm{SE}=0.110 p=.44$, cf., Table 5$)$, but no significant results were obtained for other types of learning style, beliefs on IQ and IQ scores for academic performance.

\begin{tabular}{|c|c|c|c|c|c|c|}
\hline Model & & B & SE & Beta & t & p \\
\hline \multirow{7}{*}{} & (Constant) & 7.917 & 6.325 & & 1.252 & .219 \\
\cline { 2 - 7 } & IQ belief & -.726 & .649 & -.176 & -1.119 & .271 \\
\cline { 2 - 8 } & Activist & .083 & .070 & .196 & 1.182 & .245 \\
\cline { 2 - 8 } & Reflector & .230 & .110 & .351 & 2.087 & .044 \\
\cline { 2 - 8 } & Theorist & -.042 & .098 & -.074 & -.429 & .671 \\
\cline { 2 - 8 } & Pragmatist & -.084 & .072 & -.185 & .170 & .250 \\
\cline { 2 - 8 } & IQ & .038 & .040 & .144 & .347 \\
\hline
\end{tabular}

Table 5: Multiple regression for academic performance as a dependent variable, IQ, beliefs on IQ, reflector, pragmatist, activist and theorist as predictors 


\section{Discussion}

This study investigates whether the academic performance of students in mechanical engineering can be predicted by their IQ, beliefs on IQ and with their different learning style. Results indicated that reflector learning style is significantly correlated with academic performance and predicted higher level of performance. We found no significant correlation between other types of learning style, beliefs on IQ and IQ scores with academic performance, and thus, no prediction could be made. The results of this study are in the same vein with a previous study that reported poor correlation between cognitive abilities and academic performance (Čavojová and Mikušková 2015).

Further, students with higher IQ scores are more likely to believe less on IQ, and to put more effort on learning their courses by reading, discussion, research to get into the depth and solve the problems, carefully analyze the materials and proactively contribute learning opportunities. Although, results of this study showed that a small group of students with the higher levels of IQ performed better in their courses when compared with those with lower levels of IQ. Identification of the preferred learning styles may help lecturers to improve the process of their teaching styles but, more importantly, some students, especially engineering ones, learn from tactile approaches, while others prefer auditory or visual approaches.

We then speculate that only a high level of $I Q$ does not guarantee a high academic performance and, thus, other factors need to be investigated in the future studies. Therefore, these findings imply that a high IQ is a prerequisite for higher academic success.

Further results revealed a weak correlation between the pragmatist score and GPA. However, students with a high score on pragmatism tend to get a lower GPA. Results indicated that a higher GPA was associated with higher score on reflector. This is in the same line with the findings reported by Illçin et al. (2018), which showed that students with participant learning style had higher academic performance. On the other hand, the students with a low reflector index have a low GPA, but due to the limitations of this study, low number of participants and average GPA data, there should be other variables that need to be taken into consideration. Results reported in this paper are also partially in the same line with previous studies that revealed a small positive association between level of IQ and GPA (Richardson, Abraham, and Bond 2012). Each type of learning style developed by Kolb $(1984,2006)$ comes with strengths and weaknesses. Relying on one learning style would not be sufficient and all these types are divergent, convergent, assimilative and accommodative. Indeed, learners should be able to modify different learning styles according to challenges and situations. According to Kolb (2005), the perfect learner is the one who uses each of the learning styles with strengths and weaknesses in different situations and based on the needs. For instance, a study on physiotherapy students (ilçin et al. 2018) showed collaborative learning style was more preferred and common among them, and interestingly students had better academic performance when compared with others with different learning styles.

\section{Conclusion}

In this study we emphasized on the importance of learning style of the mechanical engineering students together with $I Q$ and beliefs on IQ rather than only the role of IQ in academic performance that has been previously mentioned in traditional studies. However, because of a few limitations, this research recommends a follow up study among mechanical engineering students to be replicated when the academic life and regular classes are back to normal. 


\section{Limitations and Suggestions}

This study was conducted during Covid-19 pandemic in which students were attending their classes via online platforms. Adaptation to the new online system and, in general, the effect of the pressure of the pandemic and uncertainties need to be emphasized as we were not able to control the influence of such factors in our study. Especially the type of learning styles, which might have changed due to the changes when they experienced different modes of teaching. Therefore, replication of our study after Covid-19 pandemic is highly recommended. The other limitation that should be addressed is the sample size, which underpowered the results of this study. For example, since the majority of students had grades in the interval 1214 (out of 20), this could have influenced some research findings.

\section{References}

Abouzeid, E., S. Fouad, N. F. Wasfy, R. Alkhadragy, M. Hefny, and D. Kamal. 2021. "Influence of personality traits and learning styles on undergraduate medical students' academic achievement". Advances in Medical Education and Practice 12: 769-77. https://doi.org/10.2147/AMEP.S314644.

Akubuilo, U. C., K. K. Iloh, J. U. Onu, A. C. Ayuk, A. C. Ubesie, and A. N. Ikefuna. 2020. "Academic performance and intelligence quotient of primary school children in Enugu". Pan African Medical Journal $36 \quad$ (may-august): Article number 129. https://doi.org/10.11604/pamj.2020.36.129.22901.

Aragón, O. R., S. L. Eddy, and M. J. Graham. 2018. "Faculty beliefs about intelligence are related to the adoption of active-learning practices". CBE Life Sciences Education 17, no. 3 (september): Article number ar47. https://doi.org/10.1187/cbe.17-05-0084.

Biabani, M., and S. Izadpanah. 2019. "The study of relationship between Kolb's learning styles, gender and learning American slang by Iranian EFL students". International Journal of Instruction 12, no. 2 (april): 517-38. https://doi.org/10.29333/iji.2019.12233a.

Boström, L. 2011. "Students' learning styles compared with their teachers' learning styles in upper secondary school - a mismatched combination". Education Inquiry 2, no. 3 (september): 475-95. https://doi.org/10.3402/edui.v2i3.21995.

Bottenhorn, K. L., J. E. Bartley, M. C. Riedel, T. Salo, E. I. Bravo, R. Odean, A. Nazareth, R. W. Laird, E. D. Musser, S. M. Pruden, et al. 2021. "Intelligence and academic performance: Is it all in your head?". Preprint, submitted January 25, 2021. https://doi.org/10.1101/2021.01.23.427928.

Busato, V. V., F. J. Prins, J. J. Elshout, and C. Hamaker. 2000. "Intellectual ability, learning style, personality, achievement motivation and academic success of psychology students in higher education". Personality and Individual Differences 29, no. 6 (december): 1057-68. https://doi.org/10.1016/S0191-8869(99)00253-6.

Čavojová, V., and E. B. Mikušková. 2015. "Does intelligence predict academic achievement? Two case studies". Procedia - Social and Behavioral Sciences 174 (february): 3462-69. https://doi.org/10.1016/j.sbspro.2015.01.1019.

Chamorro-Premuzic, T., and A. Furnham. 2003. "Personality predicts academic performance: Evidence from two longitudinal university samples". Journal of Research in Personality 37, no. 4 (august): 319-38. https://doi.org/10.1016/S0092-6566(02)00578-0.

Collie, R. J., A. J. Holliman, and A. J. Martin. 2017. "Adaptability, engagement and academic achievement at university". Educational Psychology 37, no. 5 (may): 632-47. https://doi.org/10.1080/01443410.2016.1231296. 
D'Amore, A., S. James, and E. K. Mitchell. 2012. "Learning styles of first-year undergraduate nursing and midwifery students: A cross-sectional survey utilising the Kolb Learning Style Inventory". Nurse Education Today 32, no. 5 (july): 506-15. https://doi.org/10.1016/j.nedt.2011.08.001.

De Castella, K., and D. Byrne. 2015. "My intelligence may be more malleable than yours: the revised implicit theories of intelligence (self-theory) scale is a better predictor of achievement, motivation, and student disengagement". European Journal of Psychology of Education 30, no. 3 (september): 245-67. https://doi.org/10.1007/s10212-015-0244-y.

Duarte, T. M. G. P., A. M. Lopes, and L. F. M. da Silva. 2021. "Correlating entrance data and first year academic performance of students enrolled in the Integrated Master in Mechanical Engineering at the University of Porto". International Journal of Mechanical Engineering Education. Ahead of print. https://doi.org/10.1177/03064190211015650.

Felder, R. M. 1993. "Reaching the second tier: Learning and teaching styles in College Science Education". The Journal of College Science Teaching 23, no. 5: 286-90. https://www.engr.ncsu.edu/wpcontent/uploads/drive/1g7mzNhke6ErAkNXsQlyxBsmkaR-m8oe-/1993-Secondtier.pdf.

Furnham, A., T. Chamorro-Premuzic, and F. McDougall. 2003. "Personality, cognitive ability, and beliefs about intelligence as predictors of academic performance". Learning and Individual Differences 14, no. 1: 47-64. https://doi.org/10.1016/j.lindif.2003.08.002.4.

He, X., H. Wang, F. Chang, S.-E. Dill, H. Liu, B. Tang, and Y. Shi. 2021. "IQ, grit, and academic achievement: Evidence from rural China". International Journal of Educational $\begin{array}{llll}\text { Development } \quad 80 & \text { (january): } & \text { Article number } & \end{array}$ https://doi.org/10.1016/j.ijedudev.2020.102306.

İlçin, N., M. Tomruk, S. S. Yeşilyaprak, D. Karadibak, and S. Savcı. 2018. "The relationship between learning styles and academic performance in TURKISH physiotherapy students". BMC Medical Education 18, no. 1 (december): Article number 291. https://doi.org/10.1186/s12909-018-1400-2.

Jackson, D. N., and J. P. Rushton. 2006. "Males have greater g: Sex differences in general mental ability from 100,000 17- to 18-year-olds on the Scholastic Assessment Test". Intelligence 34, no. 5 (september): 479-86. https://doi.org/10.1016/j.intell.2006.03.005.

Joy, S., and D. A. Kolb. 2009. "Are there cultural differences in learning style?". International Journal of Intercultural Relations 33, no. 1 (january): 69-85. https://doi.org/10.1016/j.ijintrel.2008.11.002.

Kappe, R., and H. van der Flier. 2012. "Predicting academic success in higher education: what's more important than being smart?". European Journal of Psychology of Education 27, no. 4 (december): 605-19. https://doi.org/10.1007/s10212-011-0099-9.

Kolb, D. A. 1984. Experiential Learning: Experience as the source of learning and development. Prentice-Hall.

Kolb, D. A. 2005. Learning-style type grid (Version 3.1). Boston: Hay Group Holdings Inc.

Kolb, A., and D. A. Kolb. 2006. "Learning styles and learning spaces: A review of the multidisciplinary application of experiential learning theory in higher education". In Learning Styles and Learning: A Key to Meeting the Accountability Demands in Education, edited by R. Sims and S. Sims, 45-91. Nova Publishers.

Li, Y., and T. C. Bates. 2020. "Testing the association of growth mindset and grades across a challenging transition: Is growth mindset associated with grades?". Intelligence 81 (julyaugust): Article number 101471. https://doi.org/10.1016/j.intell.2020.101471. 
Mangels, J. A., B. Butterfield, J. Lamb, C. Good, and C. S. Dweck. 2006. "Why do beliefs about intelligence influence learning success? A social cognitive neuroscience model". Social Cognitive and Affective Neuroscience 1, no. 2 (september): 75-86. https://doi.org/10.1093/scan/nsl013.

McIntosh, D. E., F. A. Dixon, and E. E. Pierson. 2018. "Use of intelligence tests in the identification of giftedness". In Contemporary intellectual assessment: Theories, tests, and issues, edited by D. P. Flanagan and E. M. McDonough, 587-607. The Guilford Press. https://psycnet.apa.org/record/2018-36604-021.

McLaughlin, L. D. 1996. "Teaching with style (Book Review)". Journal of Instructional Psychology 23, no. 4 (december): 319-20.

https://search.ebscohost.com/login.aspx?direct=true\&AuthType=ip,shib\&db=eue\&AN=5 07537369\&lang=pt-pt\&site=ehost-live \&scope=site.

Mehta, P., and D. Kumar. 1985. "Relationships of academic achievement with intelligence, personality, adjustment, study habits and academic motivation". Journal of Personality and Clinical Studies 1, no. 1-2: 57-68. https://psycnet.apa.org/record/1988-15288-001.

Meyer, J., J. Fleckenstein, and O. Köller. 2019. "Expectancy value interactions and academic achievement: Differential relationships with achievement measures". Contemporary Educational Psychology 58 (july): 58-74. https://doi.org/10.1016/j.cedpsych.2019.01.006.

Mouw, J. T., and R. K. Khanna. 1993. "Prediction of academic success: A review of the literature and some recommendations". College Student Journal 27 no. 3: 328-36. https://psycnet.apa.org/record/1994-19467-001.

Phoong, S. Y., S. W. Phoong, and K. H. Phoong. 2021. "The influence of learning styles and motivation on undergraduate student success in mathematics". Turkish Journal of Computer and Mathematics Education (TURCOMAT) 12, no. 3: 658-65. https://doi.org/10.17762/turcomat.v12i3.771.

Raven, J., and J. H. Court. 1998. Manual for Raven's Progressive Matrices and Vocabulary Scales. Oxford: Oxford Psychologists Press.

Richardson, M., C. Abraham, and R. Bond. 2012. "Psychological correlates of university students' academic performance: a systematic review and meta-analysis". Psychological Bulletin 138, no. 2 (march): 353-87. https://doi.org/10.1037/a0026838.

Schick, R. M. 1979. "Teaching students through their individual learning styles: A practical approach. Rita Dunn and Kenneth Dunn. Reston, Va.: Reston Publishing Co., Inc., 1978". NASSP Bulletin 63, no. 428: 113. https://doi.org/10.1177/019263657906342819.

Sugarman, L. 1987. "Experiential learning: Experience as the source of learning and development, David A. Kolb, Prentice-Hall International, Hemel Hempstead, Herts., 1984. No. of pages: xiii + 256". Journal of Organizational Behavior 8, no. 4: 359-60. https://doi.org/10.1002/job.4030080408.

Suliman, W. A. 2006. "Critical thinking and learning styles of students in conventional and accelerated programmes". International Nursing Review 53, no. 1: 73-79. https://doi.org/10.1111/j.1466-7657.2006.00445.x.

Swami, V., A. Furnham, I. Maakip, M. S. Ahmad, N. H. M. Nawi, P. S. K. Voo, A. N. Christopher, and J. Garwood. 2008. "Beliefs about the meaning and measurement of intelligence: a cross-cultural comparison of American, British and Malaysian undergraduates". Applied Cognitive Psychology 22, no. 2 (march): 235-46. https://doi.org/10.1002/acp.1356.

The Jamovi Project. 2021. "Jamovi (Version 2.2.5)". [Computer Software]. https://www.jamovi.org. 
World Medical Association. 2013. "World Medical Association Declaration of Helsinki: Ethical Principles for Medical Research Involving Human Subjects". JAMA 310, no. 20: 2191-94. https://doi.org/10.1001/jama.2013.281053.

York, T. T., C. Gibson, and S. Rankin. 2015. "Defining and measuring academic success". Practical Assessment, Research, and Evaluation 20: Article 5. https://doi.org/10.7275/hz5xtx03.

Zin, N. A. M., H. B. Zaman, and S. A. M. Noah. 2002. "Multimedia mathematics tutor: matching instruction to student's learning styles". In International Conference on Computers in Education, 2002. Proceedings, 1433-34. Vol.2. https://doi.org/10.1109/CIE.2002.1186283.

\section{Acknowledgments}

The authors thank all students of the Faculty of Engineering of Universidade do Porto who accepted to voluntarily participate in this study. Authors also thank the administration of Universidade do Porto and Faculdade de Engenharia da Universidade do Porto (FEUP) for their valuable support in this study and distribution of the survey.

\section{Declaration of interest}

Authors of this manuscript have no competing interests to declare. 